\title{
Cine photography and video recording of anterior segment fluorescein angiography
}

\author{
R. J. MARSH AND S. M. FORD \\ From the Western Ophthalmic Hospital, London
}

SUMMARY A description is given of apparatus and technique for carrying out cine photography and video recording of anterior segment fluorescein angiography. We found cine best for singleframe analysis and video tape recording less expensive.

Anterior segment angiography was introduced 10 years ago on the fundus camera (Jensen and Lundback, 1968) and on the slit lamp camera 9 years ago (Brun-Jensen, 1969; Mitsui et al., 1969). It was found to provide useful information on conjunctival and corneal lesions, especially in lipid keratopathy (Bron and Easty, 1970). Abnormal vascularity of the iris is particularly well demonstrated in anterior segment ischaemia (Chignell and Easty, 1971; Marsh et al., 1974), in glaucoma (Vannas, 1969), in diabetes (Cobb, 1968; Jensen and Lundback, 1968), and after central retinal vein and artery occlusions (Raitta and Vannas, 1969; Mapstone, 1970; Kottow, 1976; Laatikainen and Blach, 1977).

One of the major photographic defects which soon becomes apparent in anterior segment angiography is that the standard machines do not give a fast enough sequence of photographs during the early phase of fluorescein filling. This is important because in diseased states of the anterior segment significant changes in the vascular pattern and permeability occur within the first 5 seconds of fluorescein appearing within the eye. In our experience with the Zeiss photo-slit lamp at best we could obtain 6 consecutive exposures at 1 second intervals, after which there was a delay of 13 seconds for recycling.

We set out therefore to develop a cine technique so that these very early stages of vascular fluorescein filling could be analysed. We decided at the same time that we should also take standard $35 \mathrm{~mm}$ pictures at $1 \cdot 5$-second intervals. The basic unit was a Carl Zeiss photo-slit lamp. The flash tube was driven by a Siemens power pack which was shared with a Zeiss fundus camera. The footpedal and motor drive were also shared. A 70/30 beam splitter was placed in the optical pathway. A standard Zeiss mic Hospital, Marylebone Road, London NW1 5YE. tube with a motorised Nikon camera back attached to it was fitted on one limb. A cone containing a Spectrotech SB5 barrier filter was mounted in the camera. The diaphragm setting on the side tube was $\mathrm{f} 16$. On the other limb of the beam splitter we connected a cine adaptor (301 587) focal length $\mathrm{F}=107$ together with a $\mathrm{C}$ thread mount containing a Spectrotech SE5 barrier filter in its upper aperture. A Beaulieu R16 cine camera was fitted to the $\mathrm{C}$ thread mount and correctly oriented (Fig. 1). This was driven by a rechargeable

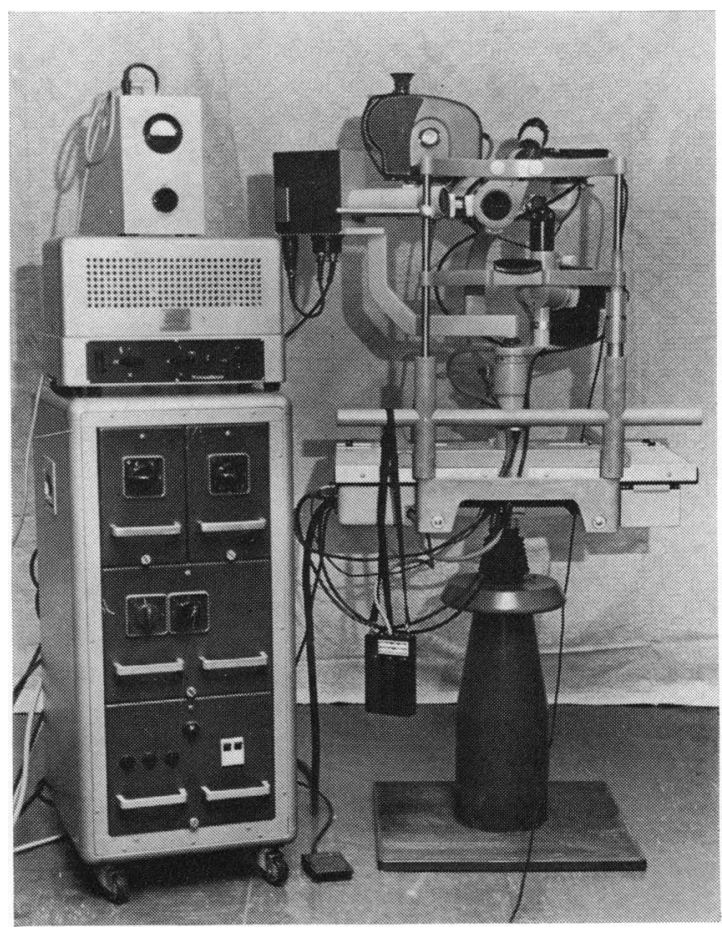

Fig. 1 Beaulieu cine camera fitted to mount 


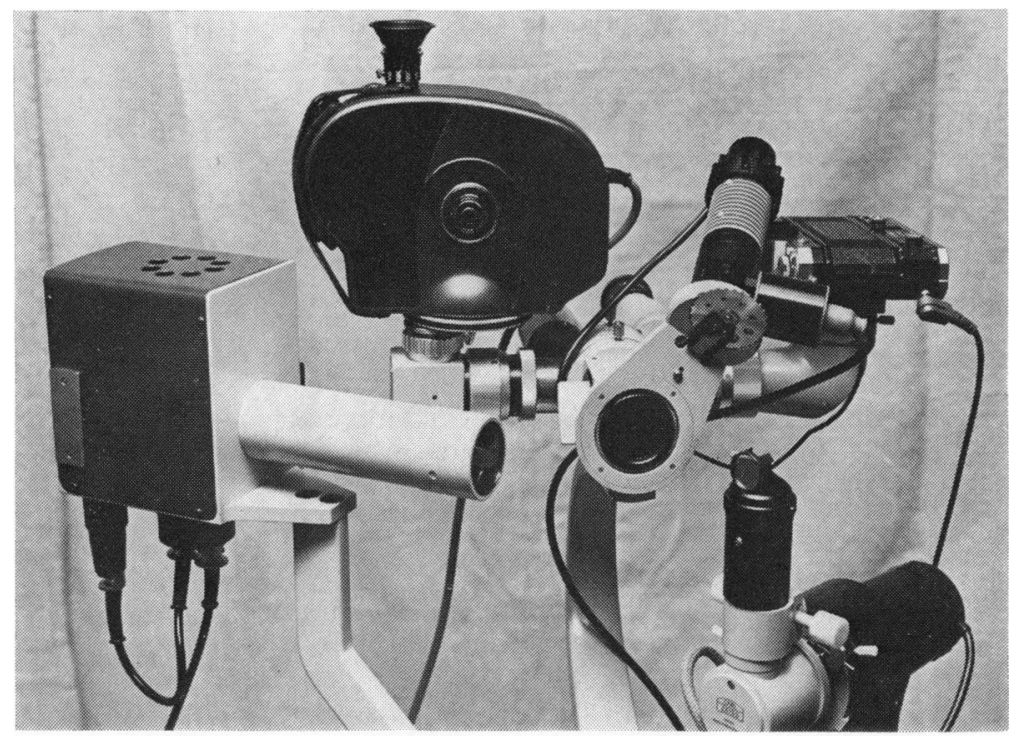

Fig. 2 Equipment for illumination

battery pack and was fired by manual control. The aperture on the camera support was set at $\mathrm{f} 7$ and the cine camera set at 12 frames per second. We found that with this combination the whole of the iris could be encompassed in one frame of the cine film. An Ilford 109 gelatin filter was cut out and fitted into 1 of the eyepieces so that fluorescence could be directly observed.

The sources of illumination were twofold. The slit beam aperture was fully opened and set at 9, and covere 1 by a Spectrotech exciter filter SB4 of $7 \mathrm{~mm}$ diameter. In front of it was opposed a -4.0 sphere lens of the same diameter. This was effective in increasing the field of illumination to encompass the whole iris. An additional halogen iris fluorescence lamp driven by an accessory power source (Carl Zeiss Oberkochen 120 VA power supply unit) was fitted on a central spindle of the photo-slit lamp and a Spectrotech exciter filter SE4 was fitted in the appropriate holder (Fig. 2). The magnification settings were as follows: for iris angiograms we found $\times 16$ to be optimal and with sectoral corneal abnormalities $\times 25$. When the machine was ready we injected $5 \mathrm{ml}$ of $20 \%$ fluorescein into an antecubital vein, and after 6 seconds the cine camera was started. The footpedal was depressed and the flash fired when fluorescein was first seen entering the anterior segment. We found that we were able to take 12 exposures at 1.5 second intervals. After this time it took a further 13 to 14 seconds for the starter to be charged for another flash.

The film used in the Nikon camera was Ilford HP5 and that in the cine camera was $16 \mathrm{~mm}$ Kodak Eastman 4-X negative film 7224. The $35 \mathrm{~mm}$ HP5 film was processed using D 76 developer for 20 minutes at $80^{\circ} \mathrm{F}\left(27^{\circ} \mathrm{C}\right)$. The cine film was processed in a methol-hydroquinone developer of D76 standard and forced developed by one stop. It was best. projected at 12 frames per second and observed in greater detail 1 frame at a time by using a Carl Zeiss Jena documator with the $16-\mathrm{mm}$ reel adaptors.

We have also adapted the technique for television monitoring. The cine camera is substituted by a CCTV (Hitachi HV 40 SU) miniature television camera. The diaphragm on the side tube was set at f11, otherwise all settings were identical to those used for cine. We viewed the angiogram on a Hitachi 75-square-inch $\left(484-\mathrm{cm}^{2}\right)$ picture video monitor VM 126AU (EK) and recorded the dye transit on a video tape recorder (National Panasonic NV 5120A).

We found that cine photography gave the best definition and single frame analysis, the best quality of all coinciding with the flash exposure on the film. The major disadvantage was the slow speed of projection required, which limited us to a small number of cine projectors, though there was also the possibility of double printing each frame of the film. We found cine film expensive, and there was a delay in the developing and printing. Video tape recording, on the other hand, can be viewed immediately, conveniently, and repeatedly during and after recording. It is especially useful for studying the vascular pattern of a lipid keratopathy prior to laser occlusion. Surprisingly, we found patients remarkably good at tolerating the very bright illumination necessarily produced by this system. 


\section{References}

Bron, A. J., and Easty, D. L. (1970). Fluorescein angiography of the globe and anterior segment. Transactions of the Ophthalmic Societies of the United Kingdom, 90, 339-367.

Brun-Jensen, J. (1969). Fluorescein angiography of the anterior segment. American Journal of Ophthalmology, 67, 842-845.

Chignell, A. H., and Easty, D. L. (1971). Iris fluorescein photography following retinal detachment and in certain ocular ischaemic conditions. Transactions of the Ophthalmic Societies of the United Kingdom, 91, 243-357.

Cobb, B. (1968). Vascular tufts at the pupillary margin. Transactions of the Ophthalmic Societies of the United Kingdom, 88, pp. 211-212.

Jensen, V. A., and Lundback, K. (1968). Fluorescence and angiography of the iris in recent and long term diabetics. Congress XVIII Ophthal. septentr. Copenhagen, 1967, Acta Ophthalmologica, 46, 584-585.

Kottow, M. (1976). Iris angiography in vascular diseases of the fundus. Documenta Ophthalmologica, 9, 465-471.
Laatikainen, L., and Blach, R. K. (1977). Behaviour of the iris vasculature in central retinal vein occlusion: a fluorescein angiographic study of the vascular response of the retina and iris. British Journal of Ophthalmology, 61, 278-284.

Mapstone, R. (1970). Ischaemia in vein occlusions. British Journal of Ophthalmology, 54, 312-315.

Marsh, R. J., Easty, D. L., and Jones, B. R. (1974). Iritis and iris atrophy in ophthalmic zoster. American Journal of Ophthalmology, 78, 255-260.

Mitsui, Y., Matsubara, M., and Kanawaga, M. (1969). Fluorescence irido-corneal photography. British Journal of Ophthalmology, 53, 505-512.

Raitta, C., and Vannas, S. (1969). Fluoreszein Angiographie der Irisgefasse nach Zentralvenenverschluss. Albrecht von Graefes Archiv für klinische und experimentelle Ophthalmologie, 177, 33-38.

Vannas, A. (1969). Fluorescein angiography of the vessels of the iris in pseudo exfoliation of the lens capsule, capsular glaucoma and some other forms of glaucoma. Acta Ophthalmologica, Suppl. 105, pp. 24 et seq. 